\title{
Impact of participatory irrigation management- case study: cocurirwa cooperative, rwamagana rice project, Rwanda
}

\begin{abstract}
Mostly swamps in Rwanda are surrounded by volcanic hills with small streams flowing to discharge runoff and seepage water. Many rice projects are implemented to develop the swamp by providing gravity irrigation facilities. Most of the projects are funded by the government and after construction the projects are handed over to rice farmer's cooperatives. These cooperatives were functioning with bureaucracy setup leading to inefficient performance resulting poor land productivity. This research has been conducted in COCURIRWA in order to bring out the quantum of costs and the benefits against the cooperative costs over a period of time and thus verify the hypothesis that benefit cost ratio of PIM system is positive. The field survey was conducted in three cooperatives (COCURIBU, CORICYA and COCURICYI) in order to collect views and suggestions from members of cooperatives studied and other stakeholders on operation and maintenance of irrigation facilities.
\end{abstract}

The results prove that through Participatory Irrigation Management the current systems of irrigation management are performing well through the involvement of progressive farmers in water distribution and collection of irrigation fees. Irrigated area is increased due to availability of sufficient water as indicated by relative water supply ratio more than one. Tail end farmers are favoured by PIM implementation resulting higher fee collection and reduction of conflicts between farmers. Farm employment generation and Paddy productivity increased significantly due to PIM. The Benefit Cost Ratio is positive as calculated from costs of activities done by cooperatives studied compared to the income generation of cooperative over the study period. With the favorable benefit-cost ratio of the three cooperatives studied, it is evident that the investment in Participatory Irrigation Management has yielded significant improvements and returns to the farmers. Thus investment in promoting Participatory Irrigation Management can be regarded as a worthwhile investment opportunity in irrigation projects in Rwanda.
Volume I Issue 3 - 2014

\author{
Kannan Narayanan \\ School of Bio systems and Environmental Engineering, Hawassa \\ University, Ethiopia
}

Correspondence: Kannan Narayanan, School of Bio systems and Environmental Engineering, Hawassa University, Ethiopia,Tel 251919155491,Email kannan051968@yahoo.co.in

Received: May 10, 2014 | Published: July 07, 2014

Keywords: farmer participation, irrigation water management, benefit cost ratio, rice cultivation, cooperatives

Abbreviations: WUA, water user associations; RRP, rwamagana rice project; PIM, participatory irrigation management; $\mathrm{BCR}$, benefit cost ratio; RRA, rural rapid appraisal; RIS, relative irrigation supply

\section{Introduction}

\section{General}

The Republic of Rwanda is one of the most poverty-stricken countries in the world. It is one of densely populated state in Africa where the total population is about 9million, resides in the total surface area, $26,338 \mathrm{~km}^{2}$. Rwanda is often called "the country of thousand hills" consisting of hills and marshlands, where around $90 \%$ or more of the population residing in rural areas are engaged in subsistence farming. About 60percent of the population still earns less than US \$1/day. For nearly two and half decades Rwanda has been facing problems of food security. This trend was exacerbated by the sad events of genocide and war of the mid-1990s. About $87 \%$ of the population lives in the rural areas on small farms of less than 1 ha with a production of $47 \%$ of the national GDP. The productivity from these farms is low due to continued land degradation by erosion and low utilization of fertilizers and other agricultural inputs.
Marshlands are estimated at 165,000 hectares from which only the half has been exploited so far for agricultural purpose. However, the pattern of exploitation of these swamps is more towards traditional methods because of lack of appropriate technology. Hitherto, inappropriate and inadequate exploitation of swamps in Rwanda has led to their irreversible degradation and continuously declining soil productivity. Faced with the above problems the Government has instituted several measures to address them. One of which is the Green Revolution. Under this a number of pathways are being pursued in order to address food security, reduce poverty, maximize crop production per unit area and improve the quality of life of the rural people. Crop production under smallholder irrigation is seen as one of the means to implement the Green Revolution. With the objective of improving food security, the Local Authority would like to reduce the water losses, expand the area under smallholder and improve on the efficiency of irrigation and thus maximize water use efficiency and land productivity. Main problems and constraints faced in on-farm irrigation management are inefficient water use, high cost of irrigation systems and quality of irrigation equipment. Excessive amount of irrigation water has been used in the existing traditional surface irrigation. ${ }^{1}$ The development strategy is now changed from quantitative oriented to qualitative oriented through 
sustainable development approach and appropriate technology for more effective use of irrigation water with high value of irrigation. Water realized around $40 \%$ of the world's food crops are produced by irrigated agriculture. The performance of irrigation and drainage is critical to the food supply and to farmers incomes, as well as to the environment. ${ }^{2}$

\section{Study background}

The ultimate goals in managing irrigation water are efficiency, equity and sustainability. Efficiency has been achieved if every drop of water has been properly allocated and used, without any waste. The goal of equity means that water is fairly distributed among users. Some farmers may have an advantage over others. Those at the head of a canal have an advantage over those living downstream, as they have first access to water. Influential farmers may have better access to water than poor farmers. In some cases, ideals of efficiency and equity may be in conflict. The goal of sustainability means that the users of today should maintain the quality and quantity of water resources for the use of future generation. Participatory irrigation management can offer one way of improving water user efficiency. ${ }^{2}$

Irrigation increases crop production by increasing crop yield cropping intensity and making possible cultivation of high value and remunerative crops. For obtaining optimum yield, water should be provided in time and in adequate quantity according to the water requirement of the crops at their various growth stages. For planning the cropping pattern, farmers need to know in advance the timing and the quantity of water supply; this was not happening satisfactorily when managed by irrigation bureaucracy; it is the reason why the responsibilities of RWAMAGANA Rice Project supported by Government of RWANDA and others NGOs are transferred to the COCURIRWA Water Users Associations (WUA) in 2005. This transfer envisages that farmers should be involved in various aspects of management of irrigation system, particularly in water distribution and collection of water rate, operation and maintenance of irrigation structure. Main problems and constraints faced on farm management of COCURIRWA are the management of water collection fees, identification of costs and benefits, quantification of costs, the comparison of costs and benefits which result in high costs of irrigation system and quality of irrigation equipment. Management of the water resources for diverse uses should incorporate a participatory approach: by involving not only the various governmental agencies but also the users and other stakeholders, in an effective and decisive manner, in various aspects of planning, design, development and management of the water resource schemes. Necessary legal and institutional changes should be made at various levels for the purpose, dully ensuring appropriate role for women. Water Users Association and local bodies such as municipalities and should particularly be involved in the operation, maintenance and management of water infrastructures/facilities at appropriate levels progressively, with a view to eventually transfer the management of such facilities to the user groups/local bodies.

Back ground of Rwamgana rice scheme: This area is located in Muhazi sector, Rwamagana district in East Province. The first phase of this project had been started in 1978 in the area of 360 ha for rice production. The production was of great efficiency from 1978 to 1982 but decreased in 1985 due to lack of financial resources, improper water management and also the decrease of soil fertility. However the productivity increased in 1986 by the loans from Rwandese Ministry of finance. From 1990 to 1994, the Rwamagana Rice project (RRP) was managed by SOPRORIZ, till the genocide war which stopped all activities of the project. The project restarted from the end of 1999 year by the government of Rwanda which encouraged the survivors of the war to go on. In these days, the rice project is getting extended in other districts of East Province such as Kayonza, Kirehe and Gatsibo, hence total area to be exploited is estimated to be 1000ha. The cooperative of COCURIRWA was created in 2002, which is under the supervision of MINAGRI through PRAUPA project. COCURIRWA is composed with inter-groups of rice cultivators (11 cooperatives) from the different swamps of Rwamagana District. COCURIRWA is a cooperative society which is created following the law no $31 / 88$ of 12 July, 1988 based on the cooperatives societies in Rwanda (Monography of Rwamagana Rice, September1990).

Climatology: The climatology of Rwamagana where COCURIRWA is located belongs to the equatorial type. The temperature and precipitation data are shown in the following (Table 1).

Table I Temperature and precipitation

\begin{tabular}{ll}
\hline Temperature $\left({ }^{\circ} \mathbf{C}\right)$ & Precipitation $(\mathbf{m m})$ \\
\hline Maximum per month: 24.70 & Maximum: 1337 \\
Minimum per month: 13.80 & Minimum: 763 \\
& Annual average: 982 \\
\hline
\end{tabular}

Source: Meteorological department, Rwanda

\section{Problems in irrigation management}

Managing irrigation so as to achieve efficiency, equity and sustainability is very difficult. Agricultural product marketing opportunities are not enough. High prices for water when it is scarce mean that low-income users may lose their access to water. Unrestricted use if prices are low may lead to pollution, water logging and over-use of groundwater. Given the special characteristics of irrigation water, there is good reason for governments to intervene and even directly manage irrigation systems. However, when a centralized agency is in charge of planning and operating an irrigation system, the result is often too much bureaucracy. Too much money is spent on staff salaries. As a result, the cost of water is high and yet the irrigation service is poor. Users are unwilling to pay their irrigation fees. The result is a vicious circle of high costs, poor services and low payment of fees, leading to inadequate funding and further deterioration of services. One way out of this difficult situation is the participatory approach to irrigation management. Users are involved at all levels, including construction and operations. It seems to give greater efficiency at a lower cost. ${ }^{2}$

\section{Participatory irrigation management}

The term Participatory Irrigation Management (PIM) refers to the participation of users (the farmers) in all aspects of irrigation management and at all levels. All aspects include planning, design, construction, operation and maintenance, financing, decision rules, Monitoring and Evaluation of the irrigation system. PIM processes build two forms of capital: productive capital (better maintained irrigation infrastructure) and social capital (new institutions such as WUAs, skills, leadership and community action). ${ }^{3}$ In the governance paradigm, PIM can be considered as a partnership between governments, agencies and users. It is unlikely that full cost recovery will be reached without formal and effective participation of all users in the management of irrigation projects. ${ }^{4}$ 


\section{Problem statement}

In Rwanda, swamps are reservoirs of water and irrigated agriculture in swamps is an important water consuming activity. Rwamagana swamp located in eastern province faces an improper management of water, the lack of link between water users and different stakeholders and the non existence of a participatory irrigation management organization for better water use which lead to decrease in productivity.

However, the sources of water in Rwamagana swamp can supply enough water for the entire developed area of the whole project during the dry season. Water misdistribution occurs over the secondary and primary canals of Rwamagana irrigation system. This misdistribution results in major differences in water availability from one tertiary unit to another. Generally the tail end portions have serious deficiencies of water whereas the head of upper sections have excess water resulting in decrease of productivity in a major part of the rice perimeter resulting permanent conflicts between farmers and even some plots are cultivated once a year. There is a need of achieving an equitable water distribution by controlling the flow distributed in the laterals and the turnouts for the cropping activities and the respective water requirements of them through a "new social contract for water" Rwamagana swamp which is managed by COCURIRWA cooperative there were a poor management of irrigation resulting in poor productivity. Since January, 2007 the general assembly of COCURIRWA has taken decision of decentralizing responsibilities to the cooperatives (11 cooperatives which compose COCURIRWA) those responsibilities are: collection of irrigation fees, operation and maintenance The benefits of these institutions are known for e.g: Increase in irrigated area, increase in agriculture production less number of conflict, better service delivery and improvement in maintenance of irrigation structures; but the capacity (skills) of WUA committee could not compare the benefits in terms of money with the investment over a period of time. Comparison of benefits with costs can give a reliable idea about the relative importance of the investment in the PIM program. It is the reason why it was decided to focus on "study of Cost-Benefit Analysis of Participatory Irrigation Management in COCURIRWA of Rwamagana rice scheme".

\section{Overall objective}

The main objectives of this study is to bring out the quantum of costs and the benefits against the project cost over a period of time and thus verify the hypothesis that benefit cost ratio of PIM is positive. Specific objectives

i. To identify the benefits related to the implementation of PIM system in COCURIRWA.

ii. To identify, quantify and valuate the costs/investment incurred and benefits obtained in implementation of a PIM project.

iii. To recommend the steps for minimizing costs and maximizing benefits and improve frame work for PIM implementation.

\section{Methodology}

\section{Study area}

The head quarter of COCURIRWA was located in Rwamagana district where the rice is processed. The COCURIRWA was divided into two main sites as follows:
Site of Rubindi: It is situated nearer to head quarter of COCURIRWA and also Northern side. There are 2dams provided for the purpose of irrigation system i.e. the dam of Gashara of $380,000 \mathrm{~m}^{3}$ capacities and Cyimpima of $340,000 \mathrm{~m}^{3}$ capacity. The drainage system is enabled by one main canal of $22 \mathrm{~km}$ length, which is constructed at the lowest point in the middle of rice cultivation. $43.5 \mathrm{~km}$ of length of irrigation canals are also provided and the masonry works are constructed along the mainly canals and where necessary in order to distribute water at desired uniform rate. Watergates, subsidiary storage, sluices, aqueducts footbridges are also provided.

Site of Gitinga, Mwambu and Kayonza: It is situated south and North-east of Rwamagana. This site uses three dams:

\section{Kayonza dam of $1,500,000 \mathrm{~m}^{3}$}

\section{Gitinga dam of $7,640,000 \mathrm{~m}^{3}$}

\section{Mwambu dam of $550,000 \mathrm{~m}^{3}$}

This site has been recently extended. The presence of much water and also the exploitation infrastructures which have been maintained are remarkable. For every dam, a number of sub-barrages are provided along the main drain at different distances from the reservoir. The water from the paddy field is collected into the main drain it is arrested by the sub-barrage at a considerable distance of dam in order to enable the good irrigation for the following paddy field. So, the sub-barrages provided on main drain are useful for raising the level of water for good irrigation of field which is so far away from the dam and difficult to use irrigation canals already constructed.

\section{Water flow and hydrology}

There is a main river flowing along each site where water comes out during heavy rainy season. The average slope of Gitinga is $2.4 \%$ for the normal discharge of $0.3 \mathrm{~m}^{3} / \mathrm{sec}$. The length of Mwambu irrigation area is $19.75 \mathrm{~km}$ for the catchments area of $74.49 \mathrm{sq} . \mathrm{km}$. The average slope of Mwambu region is $2.1 \%$ for the normal discharge of $0.15 \mathrm{~m}^{3} / \mathrm{sec}$. All these rivers have as outlet the lake of MUGESERA.

\section{Water requirement}

Water requirement may be defined as the quantity of water regardless of its source required by a crop in a given period of time for its normal growth under field conditions at a place. It includes the loses due to evapotranspiration plus loss during the application of irrigation water (unavoidable losses) and the quantity of water required for special operations such as land preparation, transplanting, leaching, etc.

\section{Water Requirement per hectare for flooding period}

i. First period from December to June: $1093 \mathrm{~m}^{3}$

ii. Second period from June to December: $933 \mathrm{~m}^{3}$

\section{Water Requirement per hectare for growth period}

i. First period: $277 \mathrm{~m}^{3}$

ii. Second period: $1138 \mathrm{~m}^{3}$

\section{Method}

In order to attain the pre-established objectives, the study was conducted in COCURIRWA Cooperative of Rwamagana Rice scheme. 
For finding the Benefit Cost Ratio (BCR), out of 11 cooperatives (WUAs) having 3 years of watering experiences after Participatory Irrigation Management (PIM); Three cooperatives (WUAs) were selected for the study to analyze performance of the cooperatives after implementing PIM (Table 2).

Table 2 Cooperatives (WUAs) selected for study.

\begin{tabular}{lll}
\hline $\begin{array}{l}\text { Name of } \\
\text { cooperative }\end{array}$ & Command area(ha) & Number of members \\
\hline COCURICYI & 61 & 302 \\
CORICYA & 73 & 388 \\
COCURIBU & 62 & 223 \\
\hline
\end{tabular}

Source: COCURIRWA documents

We have used many techniques and methods of research such the approach to the study involved participatory, focused group interviews, desktop, digital camera, field's studies which addressed the physical, social and culture environments in the perimeter. The study was undertaken by conducting interviews, using Rural Rapid Appraisal (RRA) tools, field visits, physical surveys and holding meetings with farmers (members of cooperatives) and Committee leaders (staff committee) of each cooperative. A number of methods were used to obtain information's needed. Checklist guides were used for leading group discussions. Transect walks through the schemes were made and discussions held with farmers (members). During such visits, observations and discussions were made about the general condition on the management plan, the role of farmers in planning budget, the costs of irrigation activities and governance of their cooperatives. There were open-end questions where farmers (members) and extension staff were allowed the alternative of discussing and giving ideas how their cooperatives (WUA's) must be managed.

Co-operative management: Meetings were held with the President of cooperative (WUA's), Manager and members to assess the quality and level of management. General observations were made regarding the manner in which the Staff handled the problem of management for example how to arrive distribution costs or investment to be made in the cooperative compared with the expected income (benefits).

Sampling: The survey has been done in the COCURIRWA swamps and the following zones have been targeted: CYIMPIMAMA, CYARUHOGO and BUGUGU. Where cooperative studied having their command area and taken samples as the head, middle and tail of each zone. The surveyed population was taken in targeted zones. As it is not possible to attain all farmers, a representative sample has been taken. The sample is for 81 farmers distributed in 3 zones composed by 3 sections. At the level of section, the selection of sub section was done randomly. Concerning the surveyed farmers, 9 farmers were taken randomly in each sub sector. The answers have been taken into account when concluding. The sample size is decided by using Alain Bouchard ${ }^{5}$ formula as follows:

$n=N o 1+N o N(1)$

Where, $N o=\left(t \alpha^{*} t \alpha\right) p p d 2 ; \mathrm{N}=$ Universe size $(<106$ individuals $)$ $p=$ Frequency or probability $(p=0.5) d=$ Error $(10 \%) t_{\alpha}=$ Student value $\left(\mathrm{t}_{\alpha}=1.65\right)$

The sampling was done with big, marginal and small farmers in head, middle and tail end of the project by random sampling. $\mathrm{N}=913$ farmers of cooperatives studied.
$N o=(1.65 * 1.65) *(0.5 * 0.5)(0.1) *(0.5)=68.0625 \cong 68$ $n=68 * 91368+913=63.28 \cong 63$

It means a sample of 63 persons among 913 farmers was sufficient but in order to make more accurate sample a large number have been taken for interview.

Rural rapid appraisal methodology: The aim of rapid rural appraisal is "to provide and analyze information on rural conditions as quickly as possible and to be cost effective, avoid biases and ensure the availability of results in usable format". ${ }^{6,7}$ The activities followed were: Entry-to gather information from written material, Initial walk through-to exchange observations and insights, Individual studiesfor direct observations, field measurements and informal interviews. Compare findings-to compare and correlate data and draw tentative conclusions (formal and informal meetings), Strengths and weakness of the irrigation scheme.

\section{Results and discussion}

\section{Benefits}

Benefits can be seen at two levels, primary and secondary. At both levels they can either be quantitative or qualitative.

Increase in irrigated area: Increase in irrigated area was found to be least in case of tail reach, field survey reveals that there are still uncultivated areas in the tail reach, mainly in case of BUGUGU and CYARUHOGO. They were not irrigated because the canals were damaged by cows and goats (no control of grazing) in the swamps and water does not reach the tail farmers as provided by distribution convention. At the head reach, there was no water crisis because the reservoirs were located near the head reach, so that the average increase in cultivated area per farmer was good. After implementation of PIM, the representative committee and farmers (members of cooperatives) in general assembly had taken decision to increase canal water availability which will lead to increase in irrigated area by reforming their bylaws as follows.

No grazing is allowed in the swamps or nearest watershed surrounding the swamps. If the farmers don't respect this law, they will be punished by a penalty of 10000rwfs for one cow and 1000rwfs for one goat since they damage the canals. Farmers must clean every month the canals (secondary, tertiary canals) which passing the nearest his plot. If farmers will not respect this law, they will be punished with a penalty of 10,000 rwfs.

It is found that more than $70 \%$ of the tail part farmers interviewed said that irrigated area is totally increased for rice cropping during all the rice growing season, because of water was good distributed. In general, $83 \%$ of answers have shown that, there is an increase in irrigated area and about $17 \%$ of interviewed farmers said no increase. This justifies with Participatory Irrigation Management (PIM), there are the equity in canal water availability which will read to increase in irrigated area.

Role of PIM in canal water distribution: Concerning the question about the existence of any water distribution convention, farmers gave answers as it doesn't exist; because about $70 \%$ of the tail reach farmers were of the opinion that if water distribution had continued as before (pre-PIM) they would have severe water crisis. However the farmers whose land are located in the middle and tail parts of the command area of their cooperatives wish the existence of both 
irrigation schedule and water distribution convention. Among them about $73 \%$ of interviewed farmers affirm that the intervention of PIM by forming WUAs (cooperatives) in irrigation water distribution was a unique way of problem resolution.

As expressed by the (Table 3$)$, the farmers $(85.2 \%)$ of the tail part said that the PIM is good solution for irrigation scheduling and water distribution convention; followed by the middle farmers (77.8\%). They are the farmers who mainly suffer from the poor water distribution in scheme before implementation of PIM consequently they are mainly gainer from the good water distribution after PIM. When every cooperative in COCURIRWA employs a number of watermen, they don't work as one team but each one defend interest of its cooperative and can take any serious decision about its reparations of water without contacting (meeting) with others watermen (of the other cooperatives). The suggestion is that: The PIM must be strengthened by giving more trainings and visiting the Representative committee of each cooperative (WUA's) to others cooperatives experienced in PIM. In this study the Relative irrigation water supply is determined to be 1.2 for pre-IMT period, 1.4 for post-PIM period and 1.5 for the recent situation. Considering a wide range of Relative Irrigation Supply (RIS) values from 0.41 to 4.81 among 18 different systems located in 11 countries, ${ }^{8}$ all the three values estimated in the current study could be regarded as being near 1.0. However, the results point out an increase in RIS values along the WUA's management and may be indicating an over-irrigation problem.

Table 3 Appreciation of water distribution

\begin{tabular}{lllll}
\hline \multirow{2}{*}{ Response } & \multicolumn{2}{l}{ Location } & & \multirow{2}{*}{ Total \% } \\
\cline { 2 - 4 } & Head \% & Middle \% & Tail \% & \\
\hline Favoured & 40.7 & 77.8 & 85.2 & 68 \\
Not favoured & $1 \mathrm{I} . \mathrm{I}$ & 14.8 & 3.7 & 9.8 \\
No comment & 48.2 & 7.4 & II.I & 22.2 \\
\hline
\end{tabular}

Irrigation management after PIM: According to the farmers interviewed, the answers given by different surveyed farmers to the questions about the exploitation system (grouped in cooperatives or individuals), $100 \%$ said that they are in cooperative because of implementation of PIM. The interests of those cooperatives are as follows to solve problems of conflicts in the swamp and to play a role of representing farmers in different institutions (Government or NGOs). Participatory irrigation management reforms are implemented to facilitate farmer's participation in irrigation management, through water user groups. Similar reforms are implemented as 'packages' that consist of policies, legislations and administrative structures in many Indian states. Although thousands of user groups have been formed, a closer examination of PIM reveals inefficient use of water, an opportunity for rural elites to capture social power in the name of participation and an increased gap between the rich and the poor $[9,10]$. In essence, these outcomes have highlighted the importance of understanding the complex linkages of the socio ecological and institutional settings affecting the outcomes of the PIM reforms in India.

Water management system after PIM: Normally, water management could be under the great cooperatives authority at the distribution canal. For secondary and tertiary levels farmers could be in charge of water management team where each farmer must supply water to its field according a defined convention given by the team water management. If not they will have a severe punishment. At least $92 \%$ of interviewed farmers answered that; there is a team for water use management and $8 \%$ is not informed about it. The suggestion is to explain more the role of watermen and creating a team of water management from the main intake to the plots. Contemporary participatory approaches to resource management (such as watershed and irrigation management) are programmed through 'blue print' policies which are unsuccessful. For instance, the widely known Parthasarathy Committee on Watershed Programs $\mathrm{s}^{11}$ claimed that their report was, "a detailed blueprint of a new course of watershed implementation in rainfed India" through multilayered institutional structures. ${ }^{12}$ The report, which was instrumental for the Ninth Common Guidelines ${ }^{13}$ goes beyond to claim that such government reforms hold "the key to banishing poverty" and dry land development in India. ${ }^{12}$ Often these statements are based on romantic notion of participation in the international discourse, disaggregated successes of non-governmental organizations that are deceptive in their presentation and remains a 'black-box' in the Indian democracy, are different from the way government manages resources and fail to embed with the socio-cultural, institutional and ecological settings. This does not negate the importance of policies, but calls for policies to lay out broad principles (instead of 'blue-prints') that allow multiple actors to debate and share, taking their diverse needs into consideration. Facilitating the actor's debating and sharing of principles to enable an informed water management decision remains a challenge.

\section{Irrigation fees}

Irrigation fees is an amount of money paid by farmers in compensation of investment done by the government to store and distribute water and spending linked to functioning and maintenance. It also includes other elements like: An amount for creating funds floats in order to cover the deficits especially in years with poor yield and constitute the appropriate stocks; an amount for covering the price of surveillance exerted at basin level; an amount for construction and maintenance of protection structures of network irrigation, network drainage and other elements of cooperative. The dues to be paid by the beneficiary farmers are determined according to the area of farm land under cultivation by those farmers (members of cooperative) given the power to enforce compulsory collection of these dues. Currently in COCURIRWA farmers pay 2,500rwf/plot/season.

From the (Table 4) the COCURIBU cooperative ranks first in water fees collection followed by COCURICYI and then CORICYA and it was found that with promotion of PIM, the water charges collected was increased compared with the water charges collected before decentralization. The suggestion is to strengthen the Participatory Irrigation Management (PIM) by training farmers and their representative committee. Similar studies in Turkey infer that it is known that in the pre-PIM period the fee collection performance was generally low. In 1993 the ratio of irrigation fee collection in Turkey was $33 \% .{ }^{14}$ It is also reported that in Ege region where the Kestel WUA is situated, this ratio was estimated to be $15 \%$ for the period between 1989 and 1993. ${ }^{15}$ The values estimated in the present study, for both the post- PIM and the recent situation indicate a strong collection program. According to the Monitoring and Evaluation studies carried out by Operation and Maintenance Department of the DSI, collection rates of water charges are recorded to be about $39 \%$ and $95 \%$ for Directorate of state hydraulic works and Water user organizations (WUA), respectively. ${ }^{16}$ This indicates that in the study area still there is a scope for further improvement in fee collection system. 
Paddy productivity: As informed by the representative committee and farmers productivity has increased. Due to timely availability of water, seeds, fertiliser and timely pesticides availability. After consulting the annual reports and having discussion with farmers in different meetings it is found that the production will be increased substantially every year (Table 5).

Table 4 Irrigation fees paid 2007-2009.

\begin{tabular}{lll}
\hline $\begin{array}{l}\text { Name of } \\
\text { cooperatives }\end{array}$ & \% Fees after PIM & \% Fees before PIM \\
\hline CORICYA & 44.1 & 24.4 \\
COCURICYI & 44.9 & 25.5 \\
COCURIBU & 47.8 & 27.4 \\
\hline
\end{tabular}

Table 5 Increased paddy productivity $(\mathrm{T} / \mathrm{Ha})$.

\begin{tabular}{llllll}
\hline Cooperative & 2007 & 2008 & 2009 & Av.PIM & No PIM \\
\hline CORICYA & 1.7 & 2.1 & 2.4 & 2.06 & 1.59 \\
COCURICYI & 2 & 2.25 & 2.26 & 2.17 & 1.78 \\
COCURIBU & 1.8 & 2.3 & 2.6 & 2.24 & 1.73 \\
\hline
\end{tabular}

From the calculation of the average of production per hectare it is found that COCURIBU recorded highest productivity followed by COCURICYI and then CORICYA. There is no high difference between their productions, but when compared to the productions before decentralization there is remarkable difference inferring that PIM has significant impact to increase production. It consistently appears that the productivity indicators had been deteriorating before PIM, but the decline is recovering eminently over time. Especially, the output per unit cropped area points out a significant productivity increase in the recent position. On the other hand, since other factors such as prices of the agricultural products and yield changes based on climatic volatilities may have an impact on the evolution of this indicator, the results should be considered cautiously. Both the rice productivity and profits from agriculture increased significantly due to irrigation management transfer; ${ }^{17}$ suggesting that farmer-managed irrigation system is significantly more efficient than the agencymanaged one in water delivery.

Impact on employment generation: Increase in Employment generation has been observed after the implementation of PIM directly or indirectly. Employment due to rehabilitation work of the canal-cooperatives have responsibilities to announce different jobs opportunities to their members. Employment due to operation and maintenance of the structures, employment due to administration of cooperative, for example each cooperative had engaged their own Manager but before PIM they didn't. Employment due to increase in area irrigated; for example many jobless will get employment for cultivation the big holding land farmers.

Sustainability and conflict resolution: The first sustainability indicator, the sustainability of irrigated area, was found to be higher for the recent situation, which indicates a positive development. The second sustainability indicator was area/infrastructure ratio. Since this indicator shows how much irrigated land was available to support the cost of the infrastructure, the estimated figures point to an improvement in irrigation system. This ratio would vary widely between regions based on the varying profitability of the crops grown and the intensity of the irrigation practiced. In Malaysia, area/ infrastructure ratio was ranging from 7.8 to $48.0 \mathrm{ha} / \mathrm{km}$; while in the northern USA, a figure around $35 \mathrm{ha} / \mathrm{km}$ is acceptable to support the cost of the system. ${ }^{18}$ If, however, the channel density for the Kestel Irrigation would be estimated using the command area, it would be found as $28.7 \mathrm{ha} / \mathrm{km}$. These results show that the area/infrastructure ratio changed in a positive direction; however it was low compared to its potential. It is also observed that farmers have become disciplined now, because each cooperative has conflict resolution committee which has a role of giving solution to different conflict in line with the swamp management; it can punish someone who is in violation of their bylaws and made him to pay a heavy penalty, who doesn't operate or doesn't properly maintain infrastructures under its responsibility according to the decisions of the general assembly. In case of BUGUGU, in 2008, COCURIBU collected penalty of about 14,000rwf from three farmers. Instances of penalty in CYIMPIMA (COCURICYI) 2007-2009 have been reported. Members of the cooperatives have learnt that there is no gain in breaking the rules and therefore no such cases have been reported.

\section{Benefit Cost Ratio (BCR)}

Cost can be described as the intended or untended negative effects investment. Benefits can be described then as the intended or unintended positive effect of project. The Benefit Cost Ratios have been calculated as $1.48,1.33$ and 1.38 respectively for COCURIBU, CORICYA and COCURICYI. It is found that the BCR is positive and over one. The cooperatives are in good working condition, the leading performer is COCURIBU followed by COCURICYI and then CORICYA; The suggestion given to these cooperative is that, the Executive committee of each cooperative must engage a Manager who has some skills in management for doing plan, preparing budget and the vision of cooperative for long term; in order to continue strengthening the PIM.

\section{Farmers satisfaction}

While farmer's satisfaction is considered to be a performance criterion, ${ }^{19}$ it is classified as an individual technique to evaluate performance. ${ }^{18} \mathrm{He}$ suggested that the satisfaction level of the farmers should be investigated through opinion surveys and then be combined with performance indicators. In this study, in order to evaluate the irrigation efficiency according to the views of the farmers, they were interviewed and asked questions on the timing, duration of the irrigation period and the number of water deliveries per irrigation period, the volume of water and the maintenance and repair of the scheme. Accurate fulfillment of scheme maintenance and repair services increases irrigation efficiency. In both periods, the farmers have affirmed to have an above-average level of satisfaction regarding the maintenance and repair services provided by the WUA. The level of satisfaction is found to be increased over time. According to the analysis on the data from DSI and WUA, the values of the adequacy indicator show that excessive water usage has increased during the WUA's management. In order to avoid the waste of water, it could be suggested that the WUA give priority to controlled water delivery and use and arrange for educational activities directed at the farmers. Regarding the utility and productivity, in spite of a positive evolution in the relating indicators, in the evaluation of these criteria, influence of the climatic and economical conditions should be considered as well. During the WUA's management, sustainability indicators show positive improvements. Financial efficiency is also affected positively by the IMT. The findings regarding the irrigation efficiency according 
to the views of the farmers reveal that they were generally satisfied on the timing, duration of the irrigation period and the number of the water deliveries, the volume of water and the maintenance and repair of the scheme. The farmers believe that the IMT has generally had positive or no influence on this subject. The satisfaction identified here is consistent with the finding that the excessive water use is increased under WUA's management. At this point, the need for improved control and farmer education becomes even more evident. Damage caused by lack of maintenance and location distance from the channels has found to reduce the probability of satisfaction about the WUA.

\section{Conclusion}

This research has been conducted in the aim of finding out the financial benefits against the cooperative activities costs over a period of time based on calculation of Benefit Cost Ratio through the investment in promoting Participatory Irrigation Management (PIM) in COCURIRWA. In cooperatives studied, main problems were: Low skills in management and techniques of water collection fees, Low skills in identification of costs and benefits, Low skills in Quantification of costs and benefits and Low skills in the comparison of costs and benefits. All these problems can lead cooperative to fall in low productivity. From the findings it can be seen that the PIM ultimately over a period of time, gives positive results. Most of the time, timely water is made available to farmers, due to effective and efficient water distributions system by the cooperative through PIM. This has lead to increase in exploited area and consequently to increase in income per hectare. Cooperative is also benefited, as farmers are now able to pay taxes from production, to pay timely water charges.

The benefits have largely accrued to the farmers as well as agriculture labour (in terms of higher employment opportunities), less conflict among farmers; while some benefits are also gained by the Ministry of water and natural resources (reduced cost and man power requirement). In PIM all activities related to water management are controlled by WUAs. From the favorable Benefit Cost Ratio of the three cooperative studied, it was found that BCR is positive; It is evident that the investment in PIM has yielded in high returns to the farmers because in PIM, farmers are grouped into cooperative headed by Chief Executive Officer helped by a technical committee. Out of this, it is requirement to respect rice cropping seasons in which every activity (tillage, seedling, planting, cropping practices and harvesting) is done by all farmers with minimum time gap to facilitate efficient water distribution.

The results suggest that the WUA has performed well with respect to irrigation efficiency regarding most of the performance criteria considered. It is found that the irrigation system was very successful in terms of financial efficiency; and with the management transfer to WUA, changes occurred in a positive direction in terms of utility, productivity and sustainability criteria. Nevertheless, over-irrigation and a limited sense of ownership of the irrigation system by the users were identified. Education and extension activities would result in encouraging the farmers to use the water more efficiently and to further participate in the irrigation management. Unconscious use of the scheme's facilities with an unsatisfactory sense of ownership circumvents the expected production increase and shortens the economically effective lifetime of the scheme. Thus, education and extension activities, both for the WUA's personnel and for the farmers, should be carried out in cooperation by the WUA and the Ministry of Agriculture.
Among the factors which affect the farmer's satisfaction, maintenance of the scheme is found to be a key. Compared to the structural problems inherited, maintenance is more likely to be affected by the WUA. It is understood that a better organization of the maintenance will raise the level of the farmer's satisfaction about the WUA significantly. On the other hand, achieving improved user participation, especially in terms of careful use of the channels, would play an important role in the provision of better maintenance.

\section{Acknowledgements}

None.

\section{Conflict of interest}

The author declares no conflict of interest.

\section{References}

1. Fathy E. Data Requirement for farm system design. Egypt; 2005. p. $69-74$.

2. http://irncid.org/GetFilePublication.aspx?FilePrm=4023_61739.pdf

3. http://dx.doi.org/10.1596/0-8213-4540-0

4. http://hdl.handle.net/10625/29225

5. Fred S. Land Access and poverty reduction. National University of Rwanda; 2004. p. 231-239.

6. Chambers R. The organization and operation of irrigation. An analysis of evidence from south India and Sri Lanka, United Kingdom; 1974. p. $45-48$.

7. Porter. Intervention in Small Scale. Thailand: Some Principles in Assessment; 1988. p. 123-129.

8. http://www.iwmi.cgiar.org/publications/iwmi-research-reports/iwmi-research-report-20/

9. http://www.cabdirect.org/abstracts/20056703824.html;jsessionid=D48A98E81A3BEDFA798D66F3B4A3206D

10. Swain M, Das DK. Participatory irrigation management in India: implementations and gaps. J Dev Sus Agr. 2008;3:28-39.

11. http://dolr.nic.in/ParthaCommittee/ParthaCommitteeReport.htm

12. http://www.epw.in/commentary/towards-reforms.html

13. http://dolr.nic.in/CommonGuidelines2008.pdf

14. Cevik B, Kırda C, Sayın S. Sulama Arac, Yontem ve Organizasyonu. V. Turkiye Ziraat Muhendisligi Teknik Kongresi, 17-21 Ocak 2000. Ankara, Turkiye Ziraat Muhendisleri Odası, Yayın no. 2000;38(2):959-983.

15. Yercan M, Dorsan F, U1 MA. Comparative analysis of performance criteria in irrigation schemes: a case study of Gediz River Basin in Turkey. Agric Water Manage. 2004;66(3):259-266.

16. http://yadda.icm.edu.pl/yadda/element/bwmeta1.element.elsevier-8fc4fe4b-9772-3d9e-b0fe-9fdceaf2ae44

17. Bhatta KP, Ishida A, Taniguchi K, et al. Performence of agencymanaged and farmer-managed irrigation systems: a comparative case study at Chitwan, Nepal. Irrig Drain Syst. 2005;20:177-191.

18. http://dx.doi.org/10.1596/1813-9450-4298

19. http://www.gesaaf.unifi.it/upload/sub/dipartimento/persone/professori/ trucchi/materiale \%20didattico/Lezioni/Irrigation\%20and\%20drainage\%20assessment.pdf 